\title{
Walter Benjamin Düşüncesinde Teknik: İmkanlar, Eleştiri ve Politik Eylem
}

\section{Technique in Walter Benjamin's Thought: Possibilities, Criticism and Political Action}

\author{
Murat Ertan Kardeş ${ }^{1}$
}

'İstanbul Üniversitesi, Edebiyat Fakültesi, Felsefe Bölümü, Felsefe Tarihi Anabilim Dalı, İstanbul, Türkiye

\section{ORCID: M.E.K. 0000-0003-3938-5780}

Sorumlu yazar/Corresponding author: Murat Ertan Kardeş,

İstanbul Üniversitesi, Edebiyat Fakültesi, Felsefe Bölümü, Felsefe Tarihi Anabilim Dalı, İstanbul, Türkiye

E-mail/E-posta: ertan.kardes@istanbul.edu.tr

Başvuru/Submitted: 10.05 .2020 Revizyon Talebi/Revision Requested: 17.05.2020

Son Revizyon/Last Revision Received: 19.05.2020

Kabul/Accepted: 20.05.2020

\section{Atıf/Citation:}

Kardes, Murat Ertan. (2020). "Walter Benjamin Düşüncesinde Teknik: Imkanlar, Eleştiri ve Politik Eylem" Felsefe Arkivi-Archives of Philosophy, 52: 1-18.

https://doi.org/10.26650/arcp2020-001

\section{ÖZET}

Bu yazı Walter Benjamin'in teknik kavrayışının katmanlarını göstermeyi hedeflemektedir. Onun teknik meselesi ancak deneyim ve politik eylem kavramları ekseninde anlaşılabilir. Mevcut yazı, W. Benjamin'in Scheerbart üzerine düşüncelerinden "íkinci Teknik" (zweite Technik) kavramına, kolektif beden (Leib) fikrinden deneyim (Erfahrung) anlayışına, mimarinin modern yaşamda kanonik bir özellik taşımasından devrimci eyleme filozofun teknik kavrayışının geçişliliğine vurgu yapmaktadır. "Deneyim ve Yoksulluk", "Din olarak Kapitalizm" ve "Teknik Yeniden-Üretilebilirlik Çağında Sanat Yapıtı" metinleri arasında mesele ortaklığına odaklanılmıştır. Aynı zamanda teknik ve tekniklik bahsinin metinler arasındaki ilgiyi kavramak açısından niçin bağlayıcı olduğunun üzerinde durulacaktır. Yöntem olarak filozofun erken dönem yazılarıyla son dönem yazıları arasında kopuş tezi yerine süreklilik ve tematik farklılaşma tezine sadık bir okuma sunulmaktadır. Temel iddiamız ise Walter Benjamin açısından, gerçek bir politik örgütlenmenin ikinci teknik üzerinde birinci tekniğin baskısına son verecek bir eylem olduğudur. Başka bir deyişle W. Benjamin'in teknik kavrayışı bir yandan düzenin işleyişine ilişkin radikal bir eleştiriyi diğer yandan da tüm kitlesel fantazmagoryaların kırıldığı bir politik anı içermektedir. Bu bağlamda ikinci doğa kavramı filozofun güncelliğini kavramak açısından kilit bir öneme sahiptir. Benjamin açısından gerçeklik ve ütopya ilişkisi birbirlerine paralel bir okuma stratejisine aittir. Benjamin'in kent mekanı üzerinden görünür kıldığı fantazmagoryalar aynı zamanda devrimci bir eylem için insanlığın saklı kalmış güçlerinin güncellenmesinin imkanlarını barındırmaktadır.

Anahtar Kelimeler: Walter Benjamin, teknik, deneyim, politik eylem, ikinci teknik

\section{ABSTRACT}

The purpose of this article is to indicate the dimensions of Walter Benjamin's conception of "technique". It is argued that the only way to understand his problematic technique is by considering the concepts of experience and political action. The present article emphasizes the philosopher's transitivity of technical understanding through a wide range of reflections including Benjamin's thoughts on Scheerbarts to "second technique" (zweite Technik), from his idea of collective corpus (Leib) to his understanding of experience (Erfahrung), and from the canonic 
feature of architecture in modern time to revolutionary action. We focused on the common issues in the texts of Benjamin entitled "Experience and Poverty", "Capitalism as Religion" and "The Work of Art in the Age of Mechanical Reproducibility". At the same time, we stress why the technical question and technicality are central issues in order to understand other Benjamin texts. We use the thematic continuity and differentiation thesis as a method instead of disengagement in his writings. Our essential thesis in this article is that according to Benjamin, a true political organization is an action which puts an end to the domination of the first technique over the second technique. In other words, Benjamin's conception of technique implies on the one hand a radical criticism of the existing order and on the other hand a political moment where all the phantasmagorias of the masses dissolve. In this context, the phantasmagorias, made visible through urban space, are at the same time possibilities for a revolutionary action in order to actualize the hidden forces of humanity.

Keywords: Walter Benjamin, technique, experience, political action, second technique

\section{Giriş}

Artık Walter Benjamin okumaları ve alımlamaları filozofun ne kadar materyalist ne kadar teolog olduğu veyahut bu alanların birbirleriyle ne ölçüde uyumlu ya da çelişik olduğunun soruşturması etrafında gerçekleşmemektedir. Benjamin okumalarındaki zenginleşme filozofun külliyatının bütünlüklü olarak ortaya çıkmasıyla mümkün hale gelmiştir. Onun sadece Weimar sorunları bağlamına sığdırılamayacak çaptaki çalışmalarının değeri giderek daha fazla anlaşılmıştır. 1972-1999 tarihlerinde yayımlanan ve temel referans kaynağına dönüşen Gesammelte Schriften I-VIP nin yanı sıra ilk cildi 2008 'de $^{1}$ yayımlanmaya başlayan, toplamı 21 cilt olarak tasarlanan Werke und Nachlaß başlıklı ilk toplu eleştirel edisyonu, bu zenginleşmenin tezahürleri olarak görülebilir. O halde kendisine Benjamin'de teknik sorununu odak olarak seçen bu yazı, Berlinli düşünürün deneyim ve politik eylem kavramlarını teknik kavrayışı etrafında berraklaştırmayı denemektedir. Başka bir deyişle, Benjamin' in teknik kavrayışııın çağdaş sorunlara yanıt verebilme imkanı onun "gerçek bir politika" arayışılla bağlantısını da ortaya koymaktadır.

Mevcut yazı, Benjamin'in Scheerbart üzerine düşüncelerinden "İkinci Teknik" (zweite Technik) kavramına, kolektif beden (Leib) fikrinden deneyim (Erfahrung) anlayışına, mimarinin modern yaşamda kanonik bir özellik taşımasından devrimci eyleme filozofun teknik kavrayışını gösteren unsurlara vurgu yapmaktadır. Benjamin'in metinlerine dair yöntemsel bir zorluk olan çalışmalarının parçalı ve bölüntülü olması gerçeği bu geçişliliğin gösterilmesinde işimize yarayacaktır. Aynı zamanda "teknik" ve "tekniklik" bahsinin metinler arasındaki ilgiyi kavramak açısından niçin bağlayıcı olduğunun da üzerinde durulacaktır.

Teknik meselenin bu bağlayıcıllğı şüphesiz tekniğin ne teknolojiye ne de araç ve aygitlara indirgenemezliğinde yatmaktadır. Benjamin perspektifinde, tekniğin araç olma halini mümkün kılan, tüm dönüşümleri tarihsel ve toplumsal düzlemlerde kavrayarak, süreci tersine çevirme veyahut ona yeni bir politik amaç sunma çabası vardır. Bu çaba da tekniği bir dünya tavrı olarak

1 Bkz. Walter Benjamin, Werke und Nachlaß, Kritische Gesamtausgabe, Band III: Der Begriff der Kunstkritik in der deutschen Romantik, hg. von Uwe Steiner, Berlin: Suhrkamp Verlag, 2008. 2020 başı itibariyle Cilt 3, 7, 8, 9, 10, $11,13,16$ ve 19 yayımlanmıştır. 
tüm "deneyim”, “yaşantı" ve "kolektif eylem” alanlarının içerisinde kavramayı gerektirmektedir. Bu durumda Benjamin’in erken dönem yazılarıyla son dönem yazıları arasında ilgisi kurulan kısmen yaygın kopuş tezi yerine bir süreklilik hatta tematik bir farklılaşma olduğuna dair olabildiğince sadık bir okuma sunulmaya çalışılacaktır. Böylelikle hem "deneyim" ve "kolektif beden" fikrinin çıkış noktaları incelenecek hem de bu çıkışların Benjaminci "devrimci fikrinin” oluşumundaki etkileri vurgulanacaktır.

\section{Deneyim}

Benjamin'de teknik bahsinin anlaşılmasının birinci katını deneyim kavramıyla açmak mümkündür. Benjamin, XX. yüzyılın başında üniversite kürsülerindeki hakim neo-Kantçı hocaların deneyim kavramsallaştırmalarından hoşnutsuzdur. Aslında bu hoşnutsuzluk Frankfurt Okulu filozoflarının birçoğuyla ve Martin Heidegger ile az sayıdaki ortak noktalarından biridir. Yaygın neo-Kantçılıklar (Marburg ${ }^{2}$ ve Baden Okulları ${ }^{3}$ ) ya deneyim alanının nesnelleştirilebilir bilgisine yönelme arzusu taşımaktaydılar ya da bu yönelimin bilimselci deneyim anlayışını olumlayarak onu yaşantılarla [Erlebnis] canlandırmak çabasına girişmişlerdir. Benjamin deneyimin rasyonelleştirilmesi çabasına olduğu kadar onun yaşantılarla yeniden diriltilmesi arzusuna da uzak duruyordu. Benjamin'in Immanuel Kant felsefesinin deneyim üzerinden nesnel bilgiye indirgenmesine karşı çıkmıştır. Çünkü onların bu tutumu Kant felsefesinin ufkunu matematiksel bir fizik kavrayışıyla sığlaştırmaktadır. Oysa Benjamin’in arayışı modern çağın matematiksel fizik paradigmasına sığdırılabilir yoksul bir deneyim kavramı ve içeriği değil aksine zengin ve içinde Geistige (ruhanî) boyutları olan hakiki bir deneyimdir.

Benjamin açısından felsefenin görevi deneyim kavramını kesin ve öngörülebilir bilgi ile özdeşleştirmek olamaz 4 . Benjamin'in kendi felsefî programındaki amacı deneyim kavramına hak ettiği önemi sağlayacak "üstün bir deneyim kavramı" [eines höhern Erfahrungsbegriffes] ile uğraşan bir düşünce geliştirmektir ${ }^{5}$. Benjamin Neo-Kantçlların, zamansal, ruhanî/ zihinsel bir deneyimi yok saymalarından hareketle, kendi deneyim kavramını ortaya koymaya çalışmaktadır. Benjamin, Kant’ın kendisine karşın, “üstün bir deneyim kavramını” yakaladığını düşünmektedir.

Benjamin bu program doğrultusunda üstün bir deneyim kavramı etrafında birtakım politik pratiklere katılmıştır. Eğitimci Gustav Wyneken ile tanıştığı Haubinda okulu deneyimi, gençlik hareketlerine katılımı, Berlin dışında Freiburg'da ikameti vb. süreçler Benjamin'in gençlik hareketlerinin politikliğini kavraması açısından attığı ilk tohumlardır. Tersinden söylenilecek olunursa, politikliği düşünmenin ilk adımı gençlik ve topluluk [Gemeinschaft] üzerine geliştirdiği kavrayışlardır. Benjamin’in gençlik militanlığı, devlet okullarının örgün eğitim dışında bir eğitim

2 Bkz. E. Cassirer, P. Natorp, H. Cohen, L'école de Marbourg, Paris: Les éditions du Cerf, 1998

3 Bkz. Heinrich Rickert, Science de la culture et science de la nature suivi de "Théorie de la définition", çev. M. Launay, A.H. Nicolas, C. Prompsy, Paris: Gallimard, 1997. Bkz. Heinrich Rickert, Les problèmes de la philosophie de l'histoire: une introduction, çev. B. Hébert, Toulouse: Presses Universitaire du Mirail, 1998

4 Bkz. Walter Benjamin, „Über das Programm der kommenden Philosophie“, in Gesammelte Schriften, Band II-1, Herausgegeben von RolfTiedemann und Hermann Schweppenhäuser, Frankfurt am Main : Suhrkamp, 1991, $157-$ 171 .

5 W. Benjamin, GS, II-1, 160. 
kavrayışı ${ }^{6}$ geliştirme çabalarına ortak olmasıyla başlamışıır ${ }^{7}$. Bu çabasına paralel olarak Freiburg'ta derslerini izlediği Heinrich Rickert'in neo-Kantçıllğını, Wyneken'in Kantçılık eleştirisini gözlemledi. Benjamin başlangıçtaki fikirlerini bu gençlik hareketi ve üniversite sahnelerinde ortaya koymuştur.

Berlinli düşünürün gençlik hareketlerinin zengin hedefleri olmasına rağmen başarısız olması onu yıldırmamış, bu Gemeinschaft (topluluk) arayışından teorik dersler çıkarmıştır. Benjamin'in bu dönemdeki Geistige bir Gemeinschaft arayışını Kurtul Gülenç, zihinsel çabaların politik bir kolektivitenin yerine geçemeyeceği, topluluk arayışının ise toplumsal çelişkileri aşmakta yetersiz kalacağı olarak ortaya koymaktadır ${ }^{8}$. Benjamin’in gençlik arayışı, Wilhelm dönemi burjuva Gesellschaftına (toplumuna) karşı bir tepkiyi içermekteydi. Yahudi teolojisinin Benjamin düşüncesinde konumlanışı da tam bu sebepten dolayı ne Siyonizm lehine olmuş ne de burjuva dünya yurttaşlığı ve evrenselcilik figürleri etrafında şekillenmiştir. Benjamin'in topluluk arayışı bu iki imkanın dışında bir yere işaret eder. Bu durumda Benjamin'de Yahudi kültürü de kendi sol politik seçimlerinin fikir dünyasında kalmaktadır - kendi başına bir politik yönelim olarak değil. Benjamin özel bir topluluk fikri ve deneyimi arayışını yıkan temel unsur 1. Dünya Savaşı olmuştur. Topluluk odaklı bir politik deneyim fikri kııılma yaşamıştır.

Gençlik imgesinde aradığı şey, Mektuplaşmalar'da9 görüldüğü gibi, yabancılaşmış bir toplumda atomize olmuş bireyin aşılmasına yönelik tutumların neler olabileceğidir. Berlinli filozof, özel ve bireysel bir ruh ve irade arayışıyla kurtuluşu bulma fikrine çoktan sırt çevirmiştir. $\mathrm{Bu}$ dönemde geliştirilen "dinsellik" [Religiosität ${ }^{10}$ kavramı, bireyin kendi konfor alanının ve burjuva toplumunun değerleri dışında yeni bir toplumsallıktaki arayışını anlatmaktadır. Çağın kültür krizine ve sekülerleşme olarak çağın dindışılığına (dini ya da seküler) karşı yepyeni bir eğitim kavrayışı geliştirilmektedir: Dinselliğin mekanı, üst düzey zihinselliğe sahip topluluk fikri olarak kavranmaktadır.

O halde Benjamin'in başlangıç meseleleri açısından topluluk arayışı zengin deneyimin kaynağı olarak görülmektedir. Benjamin'in küçük ve zihinsel topluluk yaratımından deneyim yoksullaşması meselesinin toplumsal boyutunu düşünmeye girişmesi arasındaki ilgi ortadadır. Benjamin topluluk üzerinden çözüm araştırma girişiminden vazgeçince, bu bahis etrafında

6 Bkz. Walter Benjamin, „Die Schulreform, eine Kulturbewegung“ içinde Gesammelte Schriften, Band II-1, Herausgegeben von Rolf Tiedemann und Hermann Schweppenhäuser, Frankfurt am Main : Suhrkamp, 1991, 1216.

7 W. Benjamin'in bu dönemki deneyimleri hakkında oldukça fazla sayıda yayın mevcuttur. Bkz. Esther Leslie, Walter Benjamin, London: Reaktion Books, 2007. Bkz. Uwe Steiner, Walter Benjamin, An Introduction to his Work and Thought, çev. M. Winkler, Chicago and London: The University of Chicago Press, 2010. Bkz. Bernd Witte, Walter Benjamin, çev. M. Tüzel, İstanbul: YKY, 2002. Ayrıca bkz. Walter Benjamin, Technique et Expérience, Mélancolie de Gauche et Autres Textes, Paris: Eterotopia France, 2016

8 Kurtul Gülenç, "Sınırda Olmak ya da Yaşamda Kalmanın Halleri”, içinde (haz.) M. Ertan Kardeş, Dar Kapıdaki Mesih, Walter Benjamin ve Politik Felsefesi, İstanbul: İthaki, 2017, 61-77.

9 Walter Benjamin, Briefe 1, 65.

10 Bkz. Walter Benjamin, "Dialog über die Religiosität der Gegenwart", içinde Gesammelte Schriften, Band II-1, Herausgegeben von Rolf Tiedemann und Hermann Schweppenhäuser, Frankfurt am Main : Suhrkamp, 1991, 1635 . 
kavradığı meseleleri başka bir toplumsallık ve gerçek bir politika arayışıyla çözümlemeye girişmiştir ${ }^{11}$.

Marino Pulliero, Otantiklik Arzusu, Walter Benjamin ve Alman Bildung Mirası başlıklı çalışmasının "Deneyim” [Erfahrung] kısmında, Benjamin'in bu ilk dönem meselelerinden hareketle üç farklı deneyim momenti yakalanabileceğini ortaya koymaktadır ${ }^{12}$ : Birincisi, filistinizmin deneyim anlayışının eleştirisi olarak Wyneken döneminin Jugendkultur ilkelerine dayalı otantik deneyim araştırması ${ }^{13}$. İkincisi Kantçı sistem içerisindeki Erfahrung kavramının kendisini merkeze alan felsefî bir eleştiri ${ }^{14}$. Üçüncüsü ise deneyim kavramının belirli bir tarih felsefesi ve yeni bir deneyim içeriği araştırmasının merkezine dönüştügü anlayışın gelişmesi. Buna göre "Deneyim ve Yoksulluk" metninden tekniğin bütün ilişkileri tersine çevirdiği dünya manzarasına ve Pulliero' nun deyimiyle deneyimin ikamesi [Ersatz] olarak Aura yitimi tartışmasına deneyim kavramı etrafında bu üç dönüştürücü momentin izlerini bulmak mümkündür ${ }^{15}$. Bu moment bir yandan kendinde özgün dinamikleri barındırmakta ancak diğer yandan da temel meselelerle yeniler birbirlerine eklemlenerek gelişmektedir.

$\mathrm{Bu}$ doğrultuda Benjamin’in "Deneyim ve Yoksulluk"16 metninde geliştirmiş olduğu kavrayışla teknik meselesi arasında ilgiyi kavramak aynı zamanda 30'lu yıllardaki tarih kavramı fikri arasındaki sürekliliğin izini sürmek kadar önemli görünmektedir. Benjamin, bu metninde, yaşlı kuşakla genç kuşak arasındaki deneyim aktarımının sözel boyutuna vurgu yapar I. Dünya Savaşıyla bu aktarımın iletilmemesi yani suskun kalınmasının büyük bir kesintiye yol açtığını vurgular. Buna göre muharebe alanlarından eve dönen askerler, "sessiz" bir şekilde dönmüşlerdir. Artık sözel iletişimi sağlayacak deneyimleri yoktur. Kuşaklardan kuşaklara geçen sözel anlatının imkanı ortadan kalkmıştır. Benjamin'e göre tekniğin gelişmesi ve yayılması insanlar arasında yeni bir tür yoksulluk oluşturmuştur. I. Dünya Savaşı bu teknik dönüşüme neden olmuştur. Bahsedilen deneyim yoksullaşması sadece özel deneyimleri değil, bütünüyle insanlığın deneyimlerini kapsamaktadır; bu da yeni bir tür barbarlıktır ${ }^{17}$.

"Deneyim ve Yoksulluk" metni Benjamin'in kolektif deneyim dışında deneyimin mümkün olmadığı tezini vurguladığı diğer metinleriyle bağdaşmaktadır. Filozofun odağı, teknik ve deneyim kaybı üzerinden ilgiyi tersine çevirmek; başka bir deyişle teknik serpilmenin yeni bir

11 Bkz. M. Ertan Kardeş, "Walter Benjamin’in Politik Felsefesine Dair Öğeler”, içinde (haz.) M. Ertan Kardeş, Dar Kapıdaki Mesih, Walter Benjamin ve Politik Felsefesi, İstanbul: İthaki, 2017, 34. :” Benjamin, ezilenlerin geleneği açısından hukuk momentinin kırıldığı bir özgürleşmeden söz eder. Benjamin "tehlikeli” addedilen Schmitt’ten bile daha radikal bir şiddet teorisi üretir aslında: Buna göre "gerçek politika" sadece "gerçek adaleti” yürürlükteki yasayı ortadan kaldırarak yaratabilecektir."

12 Marino Pulliero, Le Désir d'authenticité. Walter Benjamin et l'héritage de la Bildung allemande, Paris: Bayard, 10021005 .

13 Pulliero, a.g.e, 1002.

14 Pulliero, a.g.e, 1003.

15 Pulliero, a.g. e, $1004-1005$.

16 Bkz. Walter Benjamin, „Erfahrung und Armut“, içinde Gesammelte Schriften, Band II-1, Herausgegeben von Rolf Tiedemann und Hermann Schweppenhäuser, Frankfurt am Main : Suhrkamp, 1991, 213-219.

17 Bkz. W. Benjamin, a. g. e., 215. : "Diese Erfahrungsarmut ist Armut nicht nur an privaten sondern an Menschheitserfahrungen überhaupt. Und damit eine Art von neuem Barbarentum“. 
kolektivitenin imkanı olarak araştırılmasını sağlamaktır. Benjamin, Paul Scheerbart'ın Lesabéndio: Bir Asteroid Romanı ${ }^{18}$ kitabı üzerine yazdığı iki denemede ${ }^{19}$, insanlığın teknik ayağından hareketle kendisini daha insanca inşa edebileceğine vurgu yapar. Hiçbir aurası olmayan cam mimari ${ }^{20}$ fikrini ortaya koyan Scheerbart, varolan tekniğin nasıl ilerleyeceğine dair bir bilim kurgu yazmaktansa, tekniğin insanlığın telosu olan mutluluğa nasıl ulaşacağını tasarlayan bir bilim kurgu yazmıştır. Böylelikle Scheerbart'ın amacı "uçan arabalar” çağını resmetmektense, yepyeni bir çağın imgelerini düşlemek olmuştur. Benjamin, Scheerbart'tan hareketle "teknik pathos" unu ve "makine pathos" unu 21 düşünme imkanını bulmuştur.

Berlinli filozof açısından mimari tüm üretimin üstün ölçeği olmaya başlamıştır. Aurası olmayan cam ve iz bırakması zor olan demir konstrüksiyon ${ }^{22}$, mimarideki yeni teknikleri anlatmaktadır. Benjamin, doğadaki güçleri sömüren ve zapturapt altına alan teknik bir gelişim yerine tekniğin pathosunu kavrayan ve tekniğin tamamlanmasını insanlığın hizmetine sokmak isteyen bir okumayı gerçekleştirmektedir. "Zum Planetarium"23 metni bu ikili kavrayışı en yetkin şekilde ortaya koymaktadır. İnsanlığın gelişmesi Benjamin’in gözünde, henüz başlamaktadır; teknolojinin gelişimini insanlığın gelişmesi olarak görmek yanıltıcı olacaktır:

\begin{abstract}
"Tür olarak insan evrimini binlerce yıl önce tamamladı; tür olarak insanlık ise gelişmesine ancak şimdi başlıyor. Teknolojide, insanlığın kozmosla temasının, halklar ve aileler içindeki temasından farklı ve yeni bir biçim kazandığı bir physis düzenleniyor. İnsanlığın zamanın içlerine doğru uçsuz bucaksız yolculuklara çıkmasını mümkün kılan hız deneyimini düşünün. [...] Sahici bir kozmik deneyimin ihtilaçları, doğanın "Doğa” diye adlandırmaya alışkın olduğumuz o küçük parçasıyla sınırlı değildir. Son savaşın yıkım gecelerinde insanlığın çatısı,
\end{abstract}

18 Bkz. Paul Scheerbart, Lesabéndio: Bir Asteroid Romanı, çev. Ç. Ünaltay, İstanbul: Paris Yayınları, 2017.

19 Bkz. Walter Benjamin, „Paul Scheerbart: Lesanbéndio“, in Gesammelte Schriften, Band II-2, Herausgegeben von Rolf Tiedemann und Hermann Schweppenhäuser, Frankfurt am Main : Suhrkamp, 1991, 618-620. Bkz. Bkz. Walter Benjamin, „Sur Scheerbart“, in Gesammelte Schriften, Band II-2, Herausgegeben von Rolf Tiedemann und Hermann Schweppenhäuser, Frankfurt am Main : Suhrkamp, 1991, 630 - 632.

20 Bkz. Paul Scheerbart, Glass Architecture, çev. J. Palmes, Edited with an introd. by Dennis Sharp. New York: Praeger, 1972, 41-74.

21 Walter Benjamin, Gesammelte Schriften, Band VII-2, Herausgegeben von Rolf Tiedemann und Hermann Schweppenhäuser unter Mitarbeit von Christoph Gödde, Henri Lonitz und Gary Smith, Frankfurt am Main : Suhrkamp, 1991, 880 .

22 Bkz. Alfred Gotthold Meyer, Construire en fer, Histoire et esthétique, préface de Walter Benjamin, çev. M. Roffi, L. Biétry, Paris: InFolio, 2005. Bkz. Walter Benjamin, „Bücher, die lebendig geblieben sind „, Gesammelte Schriften, Band III, Herausgegeben von Hella Tiedemann-Bartels, 169-171. W. Benjamin edebiyat kitapları dışında sevdiği dört kitabı şu şekilde sıralamaktadır:

1) Alois Riegl, Die spätrömische Kunst-Industrie nach den Funden in Österreich-Ungarn. 1901

2) Alfred Gotthold Meyer, Eisenbauten, Ihre Geschichte und Ästhetik. 1907.

3) Franz Rosenzweig, Der Stern der Erlösung. 1921.

4) Georg Lukács. Geschichte und Klassenbewußtsein. 1923.

23 Bkz. Walter Benjamin, „Zum Planetarium“ in Einbahnstraße, Gesammelte Schriften, Band IV-1, Herausgegeben von Tillman Rexroth, Frankfurt am Main : Suhrkamp, 1991, 146-148. 
saralının saadetini andıran bir duyguyla sarsıldı. Savaşı izleyen ayaklanmalar da, bu yeni gövdeyi denetim altına alma yolunda girişilmiş ilk denemelerdi. Proletaryanın gücü, onun nekahetinin göstergesidir. Kendisini iliklerine kadar bu güçle disipline etmezse, barışçı tartışmaların hiçbiri onu kurtaramayacaktır. Yaşamakta olan, yıkımın cinnetini ancak üremenin coşkusuyla yenebilir." ${ }^{24}$

Benjamin'in, Scheerbart üzerinden geliştirdiği Jan Sieber'in "Walter Benjamin'in Teknik Kavramı" makalesinde vurguladığı gibi "kolektif beden ütopyasıdır” 25 . Sieber, Benjamin' in "gerçek bir politikacı" arayışının imkanı olarak insan ile doğa arasındaki ilişkinin teknik dolayımı kolektif bir beden (Leib) oluşturma ütopyası geliştirdiğini göstermektedir. Böylelikle Sieber, Benjamin'in teknolojik olmayan bir teknik kavramı geliştirdiğini vurgulayarak, teknik dolayımın insanlığın mutluluğu hizmetinde bir a-telos olduğunu savlamaktadır. Politika, mutluluk ve kolektif beden arasında bağlantıyı sağlar. Politik özne, özgür bir topluluğun beden olarak örgütlenmesidir. Böylelikle Lesabéndio'da doğanın bütünüyle tahakküm altına alınması düşüncesi bir kenara bırakılırken, teknik doğadan özgürleşme imkanı olarak düşünülür. Benjamin’in Scheerbart okumasından çıkan perspektif budur.

Benjamin, ilk yazılarında ortaya koyduğu teknik alete ve teknolojiye indirgenemeyecek teknik kavrayışıyla kendi ütopya kavrayışını insanın teknoloji aracılığıyla doğaya hakim olması olarak değil, insan ile doğa arasındaki yepyeni bir ilişkiselliğin keşfi olarak düşünmektedir. Filozofun bu dönemdeki kavrayışı dönüşerek ve farklılaşarak sürekliliğini diğer metinlerinde sürdürmektedir. $\mathrm{Bu}$ anlamda, Benjamin'in fiili durum ile ütopik tahayyülü aynı anda düşünmesinin bir ürünü olarak deneyim yitimi olarak teknik gelişme ve kolektif bir bedenin kurulması olarak teknik dolayımı arasındaki çift taraflılığı kavraması düşüncesinin özgünlüğüne işaret eder. Benjamin'in tarihsel deneyim ve politik praksise geçişinde bu sürekliliği yakalamak gerekmektedir. O halde deneyim yoksulluğundan kurtuluşu gözeten bir praksisi hem teknik eleştirisi olarak hem de ütopya talebi olarak kavramak gerekmektedir.

\section{Teknik Gelişme}

Ernst Jünger tarafından yayına hazırlanan "Savaş ve Savaşç" derlemesinin ${ }^{26}$ eleştirisini içeren "Alman Faşizmi Teorileri” (1930) başlıklı Benjamin yazısı bu çift taraflılığı yetkin bir şekilde göstermektedir. Benjamin, teknik gelişmenin imkan yarattığını düşünmekle birlikte, savaş yapma tarzında açığa çıkan teknolojik gelişmenin insanlığın ahlaki aydınlanmasına katkı sunmadığını savunmaktadır. Başka bir deyişle insanlığın kendi ürettiği Teknikten faydalanmasını mümkün kılacak bir politik ve toplumsal örgütlenme düzeyi yoktur. "Tür olarak insanlık gelişmesine henüz başlamaktadır” ve mevcut düzeyi itibariyle de faşizmin ve kapitalizmin felaketlerini engelleyecek

24 Walter Benjamin, “Planetarium”, çev. N. Gürbilek, içinde Son Bakışta Aşk, Walter Benjamin'den Seçme Yazılar, İstanbul: Metis, 2012, 76.

25 Jan Sieber, "Walter Benjamin’s Concept of Technique”, Anthropology \& Materialism, 4, 2019, 2.

26 Bkz. Walter Benjamin, “Theorien des Deutschen Faschismus”, in Gesammelte Schriften, Band III, Herausgegeben von Hella Tiedemann-Bartels, Frankfurt am Main : Suhrkamp, 1991, 238- 250. Ayrıca çeviri için bkz. Walter Benjamin, Estetize Edilmiş Yaşam, Sanat'tan Savaş ve Siyasete Alman Faşizminin Kuramları, sunan ve çeviren Ünsal Oskay, İstanbul: Der Yayınları, 1995, 101-126. 
bir örgütlenme biçimini üretememiştir. Benjamin, bu düzeyin gelişmesinden bağımsız teknolojik bir gelişme tezinin yarattığı patolojilerin altını çizmektedir.

Benjamin, teknik sorununun dolayım ve tarihselliğine bu sorunu nötr bir aracı olarak görmek isteyen zihniyete karşı vurgu yapmaktadır. İnsanların teknik dolayımı kendi hizmetlerine nasıl alacağı temel sorun olarak belirmektedir. Yoksa savaştaki Teknik gelişmenin yarattığı kölelik biçimlerini görmezden gelen bir araçsallık övgüsünü faşizmin dünya tasavvurunda bulmak mümkündür. O halde Benjamin teknik bahsinde, teknik ve doğa arasındaki ilişkiyi ve ortaya çıkan ürünleri sonuç olarak görürken, üretici süreç olarak insan ve doğa ilişkisini görmektedir. Benjamin, faşizmin "doğa” vurgusunu ise tam tersi bir sürecin hızlandırılması olarak okumaktadır: İnsan ve doğa dolayımı olarak teknik yerine tekniğin dolayımsız hızlandırıldığı bir sürecin idealize edilmesi.

Benjamin’in insan ve doğa dolayımında hangi ölçülerde devrimci bir ilişki üretebileceğini gösteren metni "Sürrealizm” dir². Sürrealizm fikri ile temas Benjamin için kritik bir öneme sahip olmuştur. Benjamin sürrealistlerden yasanın lağvedilmesi fikrini kapmıştır. Ancak diğer yandan Benjamin, sürrealizmin bir mirası olarak toplumsal uzlaşmadan ve yasadan kopmayı üstlenerek yasa ve özgürlük gibi uzlaşamayacak iki terimi uzlaştırmaya da yönelmiştir. Bu yüzden “Benjamin’in politik felsefesi hiç kurulmamış olan ve bizi yasanın yazgısından kurtaran daimi bir kurucu iktidar arayışıdı’”28. En basit ifadeyle Benjamin, sürrealistlerden yasa konusunda ayrışmış olsa da, devrimci imgeyi almıştır denilebilir.

Bu devrimci imge kendisini "sarhoşluğun gücünü devrime kazanmak"29 ifadesinde şiirsel bir politika arayışı olarak ortaya koymaktadır. Teknik bağlamında yorumlanırsa, kaybolmuş kozmik deneyimi yeniden tesis etmek çabası yerine, tıpkı bu kozmik deneyimde olduğu gibi yeni bir doğa ve insan ilişkisinin imkanı üzerinde durmaktadır:

\begin{abstract}
"Kolektif olanın da bir bedeni vardır [leibhaft]. Kolektif olan için teknikte kendini örgütleyen fiziksel dünya[Physis], tüm politik ve olgusal [sachlichen] gerçekliğiyle, yalnızca dindışı aydınlanışın [profane Erleuchtung] bize kapılarını açtı̆̆ı imge dünyasında [Bildraume, imge mekanı] üretilebilir. Beden ve imge dünyası [Leib und Bildraum] tüm devrimci gerilimleri kolektif bir bedensel uyarıa [Innervation], kolektifin tüm bedensel uyarılarını [Innervation] da devrimci bir boşalmaya dönüştürmek üzere teknik içinde birbirine sımsıkı kenetlendiğinde, işte yalnızca o zaman gerçeklik Komünist Manifesto'da istenen ölçüde kendini aşmış olacak”30.
\end{abstract}

27 Bkz. Walter Benjamin, „Der Sürrealismus: die letzte Momentaufnahme der europäischen Intelligenz“ içinde Gesammelte Schriften, Band II-1, Herausgegeben von Rolf Tiedemann und Hermann Schweppenhäuser, Frankfurt am Main : Suhrkamp, 1991, 295-310. Bkz. Walter Benjamin, “Gerçeküstücülük”, çev. N. Gürbilek, içinde Son Bakışta Aşk, Walter Benjamin'den Seçme Yazılar, İstanbul: Metis, 2012, 155-168.

29 W. Benjamin, a.g. e. , 308:” Die Kräfte des Rausches für die Revolution zu gewinnen“. W. Benjamin, a.g.e. , 166.

30 W. Benjamin, a.g. e., 168. 
Artık Benjamin, insan ve doğa arasında uyumlu bir deneyim arayışını bırakmakta, yerine kolektif devrimci deneyimin politik praksisle ilgisini kuracak bir kavrayışı geliştirmektedir. Gerçekliğin devrimci dönüşümü ise materyalist ve antropolojik bir potansiyelin açığa çıkarılmasıyla mümkündür. Benjamin’in sürrealizm okuması, teknik dolayımında üretilen doğanın (physisin) yeni bir gerçekliği kurmasının devrimci yöntemini anlatmaktadır. Benjamin'in bu pasajda dikkati çektiği beden mekanı, imge mekanı gibi kavramları bireysel psişik güçlerin kolektif bir yeni mekan olarak imge mekanında beden bulmasını anlatmaktadır. Teknik, Marksçı yabancılaşmanın ve şeyleşme süreçlerinin aksine bu belirlenimsizliğin kurulmasının imkanı olarak belirmektedir. Sonuçta gerçek bir gelişme tekniğin teknoloji olarak gelişmesinde değil, teknik araçsallığını kaybedip belirli bir kolektivitenin physisle ilişkisini devrimci bir şekilde dönüştürmesiyle mümkündür.

\section{Birinci Teknik ve İkinci Teknik Kavramlarının Güncelliği}

Benjamin’in “Teknik Yeniden Üretilebilirlik Çağında Sanat Yapıtı” metni hem politik eylemle ilişkisini ortaya koymak hem de tekniğe physis ile olan ilişkiler bağlamında bakışını göstermek açısından önemlidir. Ancak bu metnin elimizde farklı versiyonları mevcuttur. Werke und Nachlaß Cilt 16 beş versiyonu bir araya getirmektedir ${ }^{31}$. Beş versiyondan birincisi notlar ağırlıklı bir metin iken, dördüncüsü Fransızcadır. Bu beş versiyon arasında yaygın bir şekilde kullanılan 1939 versiyonu olan beşincisidir. Ancak başta T. W. Adorno olmak üzere ${ }^{32}$, Benjamin okurlarının önem verdiği bir kavram olan "ikinci teknik" (zweite Technik) kavramı 3. versiyonun altıncı kısmında ve yine Fransızca dördüncü versiyonunun altıncı kısmında geçmektedir. Yaygın olarak okunan 5. versiyonda yer almayan birinci ve ikinci teknik ayrımları bir yandan Benjamin yapıtındaki sürekliliğin takip edilmesine izin veren Marksçı izleği kullanan bir kavram olarak öne çıkmakta diğer yandan da bugün ekolojik krizin eşiğindeki dünyada, Benjamin düşüncesinin güncelliğinin anlaşılmasına yardım etmektedir. Dolayısıyla yazının bu kısmında Benjaminci teknik düşüncesi değer, kitle, kapitalizm, sömürü, fetişizm ve devrim gibi anahtar kavramlarla okunurken birinci ve ikinci teknik ayrımı odak alınacaktır.

31 a. Walter Benjamin, „Das Kunstwerk im Zeitalter seiner technischen Reproduzierbarkeit - Erste Fassung”, Werke und Nachlaß, Band 16, Herausgegeben von Burkhardt Lindner unter Mitarbeit von Simon Broll und Jessica Nitsche, in Das Kunstwerk im Zeitalter seiner technischen Reproduzierbarkeit, Berlin: Suhrkamp, 2013, 7-51.

b. Walter Benjamin, „Das Kunstwerk im Zeitalter seiner technischen Reproduzierbarkeit - Zweite Fassung“, a. g. e. , 52-95.

c. Walter Benjamin, „Das Kunstwerk im Zeitalter seiner technischen Reproduzierbarkeit - Dritte Fassung“, a. g. e. , $96-163$.

d. Walter Benjamin, «L'œuvre d'art à l'époque de sa reproduction mécanisée - Vierte Fassung», a. g. e. , 164 - 206.

e. Walter Benjamin, „Das Kunstwerk im Zeitalter seiner technischen Reproduzierbarkeit - Fünfte Fassung“, a. g. e. , 207-255.

32 Bkz. T. W. Adorno, Walter Benjamin Üzerine, çev. D. Muradoğlu, İstanbul: YKY, 2012, 125-126: "Biliyorsunuz, uzun yıllardır estetik denemelerimin altında "sanatın tasfiye edilmesi" konusu yatıyor. Ve müzikte teknolojinin önceliğini heyecanla savunuyor olmam, kesinlikle bu anlamda ve sizin "ikinci teknik" kavramınız anlamında anlaşılmalı”. (Londra, 18.3.1936 tarihli mektup) [tarafımızdan vurgulanmıştır]. 
“Teknik Yeniden Üretilebilirlik Çağında Sanat Yapıtı” metninin farklı versiyonları, insanlığın gelişimine bakıldığında tekniğin gelişiminin hızlı oluşunu ortaya koymaktadır. Teknik, insanlığın çiğ, olmamış politik düzeyinin ötesinde bir hıza sahiptir. İnsanın birey olarak zamansız tekniği hizmetine alması mümkün değildir. Ancak kolektif bir yaratım ile bu mümkündür. Bu bağlamda Benjamin, "ilk teknik" ile "ikinci teknik" arasında bir ayrıma gitmektedir:

"Ciddi olan ve oyun, katılık ve serbestlik sanat yapıtında farklı derecelerde sıkı sıkıya karışmışlardır. Bu da sanatın birinciyle [birinci teknikle] ikinci teknikle olduğu gibi bağlantılı olduğunu göstermektedir. Hiç şüphesiz doğa güçlerinin tahakkümü terimleri modern tekniğin [ikinci tekniğin] amacını dile getirmez; bunlar [terimler] hala birinci tekniğin diline aittir. Bu da [birinci teknik] gerçekten doğanın köleleştirilmesini gözetirken - ikincisi doğa ile insanlık arasında bir ahengi daha çok gözetir. Güncel sanatın belirleyici işlevi de insanlığı bu "ahenkli” oyuna başlatmasında yatmaktadır. Bu özellikle film için geçerlidir”³.

Benjamin ilk tekniğin amacını doğaya tahakküm kurma olarak açıklarken, ikincisini insanlarla doğa arasında açılan özgürleştirici bir oyun alanı olarak tanımlamaktadır.

Birinci teknik, insanın kendisini feda etmesi üzerine kuruludur. Ciddiyet ve katılık içermektedir. Birinci teknik insana doğa üzerinde hakimiyet kurma becerisi sağlamayı amaçlar.

33 Walter Benjamin, «L'œuvre d'art à l'époque de sa reproduction mécanisée - Vierte Fassung», a. g. e. , 173-174. Pasajın tamamı şu şekildedir:

"L'art de la préhistoire met ses notations plastiques au service de certaines pratiques, les pratiques magiques - qu'il s'agisse de tailler la figure d'un ancêtre (cet acte étant en soi-même magique); d'indiquer le mode d'exécution de ces pratiques (la statue étant dans une attitude rituelle); ou enfin, de fournir un objet de contemplation magique (la contemplation de la statue renforçant la puissance du contemplateur). Pareilles notations s'effectuaient selon les exigences d'une société à technique encore confondue avec le rituel. Technique naturellement arriérée en comparaison de la technique mécanique. Mais ce qui importe à la considération dialectique, ce n'est pas l'infériorité mécanique de cette technique, mais sa différence de tendance d'avec la nôtre - la première engageant l'homme autant que possible, la seconde le moins possible. L'exploit de la première, si l'on ose dire, est le sacrifice humain, celui de la seconde s'annoncerait dans l'avion sans pilote dirigé à distance par ondes hertziennes. Une fois pour toutes - ce fut la devise de la première technique (soit la faute irréparable, soit le sacrifice de la vie éternellement exemplaire). Une fois n'est rien - c'est la devise de la seconde technique (dont l'objet est de reprendre, en les variant inlassablement, ses expériences). L'origine de la seconde technique doit être cherchée dans le moment où, guidé par une ruse inconsciente, l'homme s'apprêta pour la première fois à se distancer de la nature. En d'autres termes: la seconde technique naquit dans le jeu.

Le sérieux et le jeu, la rigueur et la désinvolture se mêlent intimement dans l'œuvre d'art, encore qu'à différents degrés. Ceci implique que l'art est solidaire de la première comme de la seconde technique. Sans doute les termes: domination des forces naturelles n'expriment-ils le but de la technique moderne que de façon fort discutable; ils appartiennent encore au langage de la première technique. Celle-ci visait réellement à un asservissement de la nature - la seconde bien plus à une harmonie de la nature et de l'humanité. La fonction sociale décisive de l'art actuel consiste en l'initiation de l'humanité à ce jeu „harmonien». Cela vaut surtout pour le film. Le film sert à exercer l'homme à l'aperception et à la réaction déterminées par la pratique d'un équipement technique dont le rôle dans sa vie ne cesse de croître en importance. Ce rôle lui enseignera que son asservissement momentané à cet outillage ne fera place à l'affranchissement par ce même outillage que lorsque la structure économique de l'humanité se sera adaptée aux nouvelles forces productives mises en mouvement par la seconde technique. [tarafımızdan vurgulanmışırı]. 
Oysa ikinci teknik oyun ve serbestlik, rahatlık özelliği ile insanla doğa arasında bir ahenk arayışıdır. Bu haliyle bir özgürlük alanı açma kapasitesine sahiptir. Peki o zaman neden çağdaş dönemde teknik, özgürleştirici bir etki yapmadı ve niçin insanlar özgürleşmediler? Çünkü Benjamin'e göre, ikinci teknik de hala birinci tekniğin hizmetinde iş görmektedir. İkinci tekniğin özgürleştirici özellikleri kapitalist piyasa ortamına feda edilmektedir. Başka bir deyişle, kapitalist üretim biçimi, ikinci tekniğin oyun karakterini kendi tahakküm sistemine uygun olarak üretmektedir. Meta fetişizme uygun olarak birinci teknik, ikinci tekniği bastırmaktadır.

$\mathrm{Bu}$ durumda Benjamin niçin ikinci tekniğin özgürleştirici işlevinden söz etmektedir? Benjamin "antropolojik materyalizm" olarak adlandırdığı araştırma tarzı açısından, ikinci teknik tarihsel olarak ikinci değildir; birinci teknik ikinci tekniğin bozulması ve kötüye kullanılmasıdır. Zaten insanın doğa ile ilişkisi oyun üzerine kuruludur. Ancak toplumsal örgütlenmelerdeki aciliyet her zaman için ciddi, kestirebilir ve katı olanı gerektirir. Bir nevi tekniğin ortaya çıkışında oyun öğesi ("ludique”) tahakküm lehine bir seçimle ortadan kaldırılmıştır. Oyunsal ilişkinin yaratıcılığından faydalanılırken, bu yaratıcılığın özgürleştirici kısımları ortadan kaldırılmaktadır.

Benjamin terminolojisinde tekniğin, teknolojiye ve onun ürünü olan aletlere, makinelere indirgenememesinin sebebi burada yatmaktadır. Modernlikte teknik kullanımı ikinci tekniğin birikimini, birincisinin yöntemlerle rasyonelleştirmesi üzerine kuruludur. Dolayısıyla bu rasyonelleştirme ve şiddet ilişkisi insanın sadece doğa üzerinde tahakkümünü değil aynı zamanda insanın kendi üzerindeki tahakkümünü de giderek artırmaktadır. Modern teknik, kapitalizme has üretim ve tüketim ilişkileri tarafından kendisini geliştirerek örgütlenmektedir. $O$ halde teknik kendinde iyidir ya da kendinde kötüdür düşüncesi yerine, Benjamin, ikinci tekniğin nasıl bir politik ve ekonomik düzende geliştirildiğinin altını çizmektedir. Benjamin kendi devrimci politikasını da ikinci teknik üzerinde birinci tekniğin baskısına son verecek bir örgütlenmeyle tanımlamaktadır. "Devrimler" onun gözünde "kolektif öğenin (sinirsel) uyarılmalarıdır [innervation], ya da, daha açık olarak ilk defa ikinci teknikte organların bulan kolektivitenin uyarlma girişimleridir" 34 .

34 Walter Benjamin, a. g. e. : "[1]Le but même des révolutions est d'accélérer cette adaptation. Les révolutions sont les innervations de l'élément collectif ou, plus exactement, les tentatives d'innervation de la collectivité qui pour la première fois trouve ses organes dans la seconde technique. Cette technique constitue un système qui exige que les forces sociales élémentaires soient subjuguées pour que puisse s'établir un jeu „harmonien» entre les forces naturelles et l'homme. Et de même qu'un enfant qui apprend à saisir tend la main vers la lune comme vers une balle à sa portée - l'humanité, dans ses tentatives d'innervation, envisage, à côté des buts accessibles, d'autres qui ne sont d'abord qu'utopiques. Car ce n'est pas seulement la seconde technique qui, dans les révolutions, annonce les revendications qu'elle adressera à la société. C'est précisément parce que cette technique ne vise qu'à libérer davantage l'homme de ses corvées que l'individu voit tout d'un coup son champ d'action s'étendre, incommensurable. Dans ce champ, il ne sait encore s’orienter. Mais il y affirme déjà ses revendications. Car plus l'élément collectif s'approprie sa seconde technique, plus l'individu éprouve combien limité, sous l'emprise de la première technique, avait été le domaine de ses possibilités. Bref, c'est l'individu particulier, émancipé par la liquidation de la première technique, qui revendique ses droits. Or, la seconde technique est à peine assurée de ses premières acquisitions révolutionnaires, que déjà les instances vitales de l'individu, réprimées du fait de la première technique - l'amour et la mort - aspirent à s'imposer avec une nouvelle vigueur. L'œuvre de Fourier constitue l'un des plus importants documents historiques de cette revendication». [tarafımızdan vurgulanmıştır]. 
"Alman Faşizmi Teorileri” metnine dönülecek olursa, Benjamin tekniği doğayı dil olarak erişmeye sağlayacak güç olarak tanımlamıştı. Faşizm ise bu durumda doğanın sessizliğe bürünmesidir. Askerler evlerine suskun ve aktarılacak deneyimi olmadan dönerler. Benjamin açısından devrim teknik dolayımında doğayla kurulacak yeni bir dilin adıdır; varolan ilişki biçimlerinin lehçelerinden biri değil. Bu ise ancak ikinci tekniğin kurtulmasıyla mümkündür.

Benjamin literatürünün en önemli araştırmacılarından Irving Wohlfarth, "birinci teknik" ve "ikinci teknik" kavramlarının Hegel, Marx ve Lukács'tan miras “ikinci doğa” kavramından hareketle oluşturulduğunu düşünmektedir ${ }^{35}$. İkinci doğa basitçe insanın kendisini içinde bulduğu fiziki doğa üzerine inşa ettiği yaşadığı dünyasıdır; ancak bu inşa o kadar katılaşmış ve yabancılaşmıştır ki insanın dışında ya da ona karşıt bir konum olarak kendisini ortaya koyabilir. Doğa tarihi ile politik-ekonominin tarihi arasında belirli bir ilgi dahilinde ayrım söz konusudur. Marksçı literatür açısından Lukács'ın Tarih ve SınıfBilincỉ ndeki konumu kapitalizmin gelişimiyle doğanın toplumsal olarak inşa edilen bir kategori olduğudur. Doğanın "doğal” sayılması, doğanın tarihsel olarak kavrayışlarının değişmediği anlamına gelmemektedir. Aksine doğanın tanımı da kavrayışı da tarihsel toplumsal süreçlerde şekillenmektedir. O halde birinci doğanın yanında insanın kurduğu yaşam ikinci doğa olarak düşünülürken, birinci doğanın içlemi ikinci doğayla birlikte anlaşılmaktadır. İkinci doğa, kültür, alışkanlık, eğitim ve toplumsal yaşam alanlarını kapsamaktadır. Böylelikle ikisi arasındaki ilişki şeyleşmiş ilişkinin tarihini anlatmaktadır ${ }^{36}$.

35 Bkz. Irving Wohlfarth, "Spielraum . Jeu et enjeu de la «seconde technique» chez Walter Benjamin», içinde Anthropologischer Materialismus, Materialismus der Begegnung \& MoMo Berlin Philosophische KonTexte, Band 4, Marc Berdet / Thomas Ebke (dir./Hg.) 2014, 93. Bkz. Georg (György) Lukács, Roman Kuramı, çev. C. Soydemir, İstanbul: Metis, 2003, 71-72. :"İkinci doğa, insan elinden çıkma yapıların doğası, lirik tözsellikten yoksundur; biçimleri fazla katıdır ve kendilerini simge-yaratıcı âna uyarlayamazlar; ikinci doğanın kendi yasalarınca üretilmiş içeriği, lirik şiire girdiğinde fazla denemesel kaçmaya mahkûm öğelerden arınamayacak kadar kesindir; üstelik, bu öğeler o kadar yasaların insafına kalmış durumdadırlar, yasalardan bağımsız bir varoluşun duyusal değerinden o kadar yoksundurlar ki, yasalar olmaksızın ancak parçalanıp yok olabilirler. Birinci doğa dilsiz, duyusal ama anlamdan yoksundur - İkincisi böyle değil: Katı ve yabancı hale gelmiş ve artık içsellik uyandırmayan bir anlamlar bütünüdür; çoktan ölmüş içselliklerin mahzen mezarıdır; bu ikinci doğa -mümkün olsaydı- ancak başlangıçta veya ideal varoluşta onu yaratmış veya korumuş olan ruhların metafizik diriltilmesiyle canlanabilirdi; ama başka bir içselliğin onu canlandırması imkânsızdır. Ruh, ikinci doğayı sadece duygu durumlarının malzemesine indirgeyemez, çünkü ikinci doğa bu açıdan fazla yakındır ruhun kendi özlem ve beklentilerine; ama ikinci doğa bu beklentilerin uygun ve yeterli ifadeleri olamayacak kadar da uzak ve yabancıdır. Doğaya (birinci doğaya) yabancılaşma, doğa karşısındaki modem duygusal tutum, insanın kendi eliyle yarattığı çevresinin bir aile yuvası değil de bir hapishane olduğu gerçeğinin dışa yansıtılmasıdır sadece”.

36 Bkz. György Lukács, Tarih ve Sınıf Bilinci, çev. Y. Öner, İstanbul: Belge, 1998, 161. : "Çünkü metayı kendi sahteleştirilmemiş niteliğiyle kavramak ancak tüm toplumsal varlığın evrensel kategorisi çerçevesinde mümkündür. Meta ilişkisiyle ortaya çıkan şeyleşme, gerek toplumun nesnel gelişimi gerekse insanın toplumsal davranışı açısından ancak bu bağlam çerçevesinde kesin bir anlam kazanır; ayrıca hem insanların bilinçlerinin bu şeyleşmeyi ifade eden biçimlere boyun eğmesi açısından, hem de bu süreci kavrama ya da sürecin yıkıcı etkilerine karşı direnmek, üstelik böylece oluşan “ikinci doğa” nın koşullarında kölelikten kurtulma çabaları açısından. (...) Şeyleşme denen temel fenomeni Marx şöyle betimliyor: Ürünün meta şeklinde esrarengiz olan şey, bu şeklin insanlara kendi emeklerinin toplumsal karakterini düpedüz emek ürününün nesnel karakteri olarak, bu şeylerin toplumdaki doğal [...] özellikleri olarak yansıtmasıdır”. 
“Teknik Yeniden-Üretilebilirlik Çağında Sanat Yapıtı" metnindeki "kült" ve "sergileme" arasında yapılan ayrım yorumlanacak olunursa, otantik sanat yapıtı benzersizdir, temeli külte dayanmaktadır. Sanat yapıtının kült değerine karşın sergileme değeri ise çağdaş yenidenüretilebilir teknikleriyle belirmiştir. Kült değeri yapıtın biricikliği, sergileme değeri ise biricikliği parçalayan fotoğraf ve sinema gibi yeni dalları ortaya çıkarmıştır. Benjamin, kült değeri olan yapıtları birinci teknikle, sergilemeye açık ve sınırsı sayıda yeniden-üretilebilir yapıtları ise ikinci teknikle anmaktadır. Benjamin’in gözünde, "Bütün seferler için bir kereliğine" [Une fois pour toutes] düsturu birinciyi anlatırken, "Bir kere hiç olmamıştır" [Une fois n’est rien] ikinci tekniğe gönderme yapmaktadır. İkincisi modern dünyanın teknik düzeyini anlatmaktadır. Böylelikle doğadan uzaklaşmayı öğrenen kendisini “bilinçdışı bir kurnazlık” [une ruse inconscient] tarafından yönlendirilen, ikinci tekniğin doğduğu oyun alanında bulmaktadır.

Hiç şüphesiz Benjamin bu oyun alanında, ikinci doğanın tamamen dönüştürüldüğü kolektivitenin imkanını yakalamaktadır. Esas mesele kapitalist üretim biçimlerinin hizmetindeki tekniğin, devrimci bir doğa tasarımı süreciyle düşünülmesidir. Tekrarlanılacak olunursa, Benjamin için insanlık bu gelişimi kaydetmek açısından henüz emekleme aşamasındandır. Wohlfarth, faşizmin arkaik feda ediş ve köken fikirlerini çokça kullanan doğaya dönüş fikrine karşın, buradaki ilk doğa fikrinin sonradan işe katılan sahte bir kült olduğunu vurgulamaktadır; bu bağlamda Benjamin’ in "devrimci kolektifi” nin ikinci tekniği kendi physisi, yani kendi "birinci ikinci doğası" yapmaya uğraşmaktadır ${ }^{37}$.

Benjamin, birinci ve ikinci tekniğin arasında yepyeni bir ilişkinin keşfi üzerine odaklanmaktadır. Böylelikle Wohlfarth, Herbert Marcuse’ye atıfla Benjamin’in "antropolojik materyalizm” ve "ikinci teknik" gibi kavramlarının "kurtuluş", "mutluluk" gibi kavramlarına nazaran hem geleceğinin olduğunu hem de bu kavramlarla şimdi arasında oluşan kopuşu azalttığının altını çizmektedir ${ }^{38}$. İkinci teknik kavramı dolayısıyla Benjamin’i Weimar konjonktürünün tarihsel bir örneği olarak okuyabilecek bir yaklaşıma karşı, filozofun tüm kavramsal çerçevesinin sürmekte olan ve adına istikrar ve büyüme denilen süreçler içerisinde güncellenmesine izin veren anahtar işlevi de görmektedir.

\section{Kent, Mimarlık ve Teknik}

Benjamin sanat yapıtı sorusunu özgün olanın kopyası (ya kopyanın kopyası) ya da sanatçının tekil dehası sorunu ötesine taşımayı başarmıştır. Artık sanat ve deneyim ilişkisi otantiklik meselesi dışında ele alınmaktadır. Dolayısıyla Benjamin’in doğayla yeni bir ilişki kurma çabasına "doğaya dönüş” fikri de kapitalizmin farklı bir meta sistemine geçiş fikri de yabancıdır. Şeyleşme teorisi otantikliği, fetişizm eleştirisi ise kapitalizm içinde daha adil bir dolaşımı arzulamamaktadır. Aura yitimi sanatı öldürmediği gibi, aura yitimi sonrası çă̆ bütünüyle yozlaşmayı anlatmamaktadır. Auranın yitimi ve geleneğin sarsılması gibi modern fenomenler tekniğin yeniden üretim süreçlerinde barbarlıktan kurtulma imkanlarını da barındırmaktadır.

37 Irving Wohlfarth, a. g. e., 110.

38 Irving Wohlfarth, a.g. e., 131. 
Teknik yeniden-üretilebilirlik çağında uygarlığın/barbarlığın örgütlendiği mekanı, kenti, bu imkanlar açısından nasıl ele almak gerekmektedir? Kent, teknik yetkinliğin ve uzmanlığın aracılığıyla doğa ve tarih ilişkilerinin temel politik sahnesidir. Kent pratiklerini anlamadan deneyim sorununu ve teknikliğin bizi çevreleyen dünyasını çözümlemeye girişmek Benjamin özelinde imkansız olacaktır. Başta Passagenwerk ${ }^{39}$ projesi olmak üzere Berlin, Ibiza, Paris ve Moskova gibi kentlerle kurulan özel ilgi ve mimariye düşüncesinde biçtiği özel rol bu zorunluluğu ortaya koymaktadır. Kent, bu çerçevede, modernliğin sorunlarının beşiğidir.

Pasajlar Çalışması "XIX. Yüzyılın Başkenti Paris" 1935 versiyonu "Haussmann ya da Barikatlar” (VI. başlık) kısmında, Haussmann’ın kent planlama stratejisinin nasıl teknik zorunlulukları sanatsal hedeflerle süsleyerek hakim sınıfın egemenliğini her anlamda pekiştirdiğini göstermektedir ${ }^{40}$. Buna göre geniş caddelerin inşasında barikatların bir daha kurulmamasını hedeflerken aynı zamanda Paris kent mekanının finansal çevrelerin taleplerine uygun bir şekilde "düzenlenmesi” de söz konusudur. Bu nötr bir güzelleştirme algısı yaratmakla birlikte stratejik amacı olası isyanlara ve kalkışmalara karşı sermayeyi güvence alına almaktır.

Kentin "stratejik güzelleştirmeye" 41 tabi tutulması kentsel planlamanın teknik nötralitesinin politik amaçlarını gizleyen bir araç olması durumunu yetkin bir şekilde anlatmaktadır. Kent güzelleştirilecektir, güzelleştirme ise teknik üstünlüğe ve tarafsızlığa sahiptir. Ancak bu teknik tarafsızlı̆̆ın bizzat kendisi tarafsız değildir. Kent mekanı, hakim sınıfın galibiyetini perçinleyen ve mağlupları bütün seferler için dışarıda bırakan bir güzelleştirme ideolojisiyle politikadan arındırılmaktadır. Dışarıda bırakılanlar her şeyden önce politik eylemden yoksun bırakılmıştır.

Benjamin'in ortaya koyduğu gibi III. Napolyon zamanında kenti "güzelleştirme” yurttaşlar alanına dair pratikleri, hakim yönetim teknikleri açısından zapturapt altına alma çabasını içermektedir. Güzelleştirme, kent mekanında yaşayan yurttaşların politik özne olmalarını yitirmesini ve genel olarak üretim süreçlerinin şeyleymiş unsurları olmasını öngörmektedir ${ }^{42}$.

39 Walter Benjamin, Gesammelte Schriften, V.I, Herausgegeben von RolfTiedemann, Frankfurt am Main : Suhrkamp, 1991.

40 Walter Benjamin, GS, V-1, 56-57. Walter Benjamin, “XIX. Yüzyıl'ın Başkenti Paris”, içinde Pasajlar, çev. A. Cemal, İstanbul: YKY, 2002, 87. Türkçe'de Pasajlar ismiyle yayımlanan kitabın Benjamin literatüründe Das Passagen-werk, Le livre des Passage, The Arcades Project adlarıyla yayımlanmış kitapların içeriklerinden oldukça farklıdır. Zaten A. Cemal de bu devasa farkı girişte vurgulamaktadır. Türkçe edisyon sadece "XIX. Yüzyıl'ın Başkenti Paris”, "Charles Baudelaire: Kapitalizmin Yükseliş Çağında Bir Lirik Şair”, "Baudelaire’de Bazı Motifler Üzerine”, 15 sayfalık "İlk Taslaklar" kısımlarını içerirken kitaba "Tarih Kavramı Üzerine” ve "Tekniğin Olanaklarıyla Yeniden Üretilebildiği Çağda Sanat Yapıtı” metinleri eklenmiştir. Oysa Pasajlar ya da Pasajlar Çalışması olarak bilinen "XIX. Yüzyılın Başkenti Paris”in 1935 ve 1939 versiyonlarının yanı sıra A’dan Z'ye kadar kodlanmış 25 başlıktan, a'dan r'ye (c, e, f, h, n, o, q, s, t, u, v, w başlıkları mevcut değiller) kadar kodlanmış 10 başlıktan, proje notlarından, taslaklarından ve eklerinden oluşmaktadır. Kodlanmış başlıklar Benjamin’in, bütünlüklü bir metin haline getirmek istediği yüzlerce alıntıdan meydana gelmektedir. Başlıklar alında, alıntılar dışında Benjamin’in konu ile ilgili düşünceleri, aforizmaları ve notları bulunmaktadır. Ayrıca Benjamin’in Baudelaire üzerine denemeleri bu çalışma ile paralel olarak yürütülmüş çalışmasının ürünleridir.

41 Walter Benjamin, GS, V-1, 57. : «L'embellissement stratégique”.

42 Bu hususta Henri Lefebvre’in çalışmalarını belirli açılardan W. Benjaminci izlek bağlamında değerlendirmek mümkündür. Bkz. Henri Lefebvre, Le Droit à la Ville; suivi de Espace et Politique, Paris: Anthropos, 1974. Bkz. Henri Lefebvre, La révolution urbaine, Paris: Gallimard, 1970 
Atomize bireyler önce araçsallaştırılmış ilişki biçimlerinde yaşayabilirlerken, duyumsadıkları gerçeklik ne dışlandıkları bir çemberdir ne de bu çemberi kıracak eylemlerini imkansız kılan bir düzendir.

Bu anlamda "Komün” başlığını taşıyan "k" başlığı, kent mekanında bastırılmış politik eylemin şiddetli geri dönüşünü konu edinmektedir. Karışık notlardan oluşan bu kısım, mimari teknikle "güzelleştirilen” kentin, hakim sınıfın kullanım taleplerine ve onları mekansal bölümlenmelerine indirgenemeyeceğinin bir hatırlatmasıdır. "Ezilenlerin geleneğinin” güncellenmesidir. "Komünün bütünüyle 1793 'ün mirasçısı olma duygusu vardı" [k1, 3] ${ }^{43}$. Benjamin, devrimci süreçlerle burjuva arasında kurulacak uyuşma fikrine de karşı çıkmaktaydı. Benjamin’in açısından komünün tarihsel akıştaki sürekliliği kesintiye uğratması, geçmişin acılarının da hesabının sorulması olarak belirmektedir. Kesintiye uğrayan iktidar pratikleri ve tarihsel haksızlardır. Böylelikle bu kesinti başka bir gelenekteki - ezilenlerin geleneğindeki - sürekliliğin önünü açmaktadır.

Benjamin’in tarih kavrayışı Marx’’n bilinç reformuyla uyuşmaktadır. Buna göre Benjamin [K1, 3]'te şunu yazmaktadır: "Yeni diyalektik tarih bilimi, şimdiyi, uyanılmış bir dünya olarak görme sanatı şeklinde sunmaktadır. Bu uyanılmış şimdi aslında, evvel zaman adını verdiğimiz düşle ilişkilidir. Evvel zamanı düşün hatırlanmasında yeniden kurmak! Bu şekilde anımsama [Erinnerung] ile uyanma [Erwachen] yakından bağlantılı hale gelir. Uyanma, aslında yeniden anmanın diyalektiğidir, uyanma Kopernik devrimidir” ${ }^{4}$. Ne geçmiş geçmiştir, ne de gelecek tükenmiştir. Uyanma tüm zamanlarda ilişkinin yeniden sorgulanmasıdır. Şimdi, geçmişin çağrısına her an yanıt verebilir durumda olmayı içerir.

Gerçek bir tarihsel kırılma, zamansal akışta sıçrama ile mümkündür. Teknik ilerlemenin dünyasında sisteme has çelişkilerin derinleşmesini beklemek, kitlesel savaşlara ve sonunda faşizme teslim olmayı getirecektir. “Toplumsal hareket”ler (a başlı̆̆ı) arasında sadece barikat pratiği bu fantazmagoryaların uygarlık anlayışlarını çözündürebilir. Fantazmagoryalar, gerçekliğin üretiminin nasıl gerçekleştirildiğinin unutulmasına yaslanırlar; bastırma mekanizmaları, gerçekliği anlamlandırma girişimleri, şeyleşme ve metanın fetiş karakteri vb. Benjamin için devrimci eylem insanlığın saklı güçlerinin güncellenmesidir.

\section{Sonuç}

Benjamin'de teknik kavrayışı ancak düzenin işleyişine dair politik eleştiriyi yapmakla anlaşılabilir. Peki bu durumda günümüz dünyasında Benjaminci teknik kavrayışı nasıl güncelliğini korumaktadır? Bu soru, antroposenin nimetlerine bel bağlayanların, "küreselleşme ile özelleştirme arasındaki kutsal ittifakın empoze ettiği yeni ikinci doğa” ${ }^{45}$ kavrayışının ve yapay zekanın erdemlerine ümit besleyenlerin olduğu bir zaman aralığında, büyümeci küresel neoliberalizmin ne ölçüde yola devam edebilir olduğu ile paraleldir. Kitle yalnızlığında giderek

43 Walter Benjamin, a.g. e., 950. Walter Benjamin, Paris capitale du XIXe siècle. Le livre des passages, trad. Jean Lacoste, Paris: le Cerf, 2002, 789.

44 Walter Benjamin, a.g.e., 491. Walter Benjamin, , a. g. e., 406.

45 I. Wohlfarth, a.g.e. 
ezilen atomize bireylerin sanal ya da gerçek konforlu alanları ne kadar daha süre toplumsal fantazmagorya etkisi sürdürebilir?

Atomize birey herhangi bir kolektivitenin parçası olamadan büyük bir niceliksel corpusa dahil olmaktadır. Kişisel çıkarcılığın erdem olduğu bir ekonomik-toplum düzeninde, bir şekilde corpusa dahil olmak bile konformist zihniyetleri rahatsız etmektedir; oysa bir ekonomiktoplumsal yapı içinde konformist egoların yanyanalığı ideolojidir. Meta fetişizm düzeni, yapay zekaların gelişmesiyle insanlığın düze çıkacağını varsaymanın, insanları getireceği yer ise küresel liberal değerlerin toplumsal sistemlerde daha fazla yerleşik hale gelmesi olmayacaktır. Bu tarz yanılsamalara Walter Benjamin Birinci Dünya Savaşı öncesi dünyada tanık olmuştu.

Michael Löwy'nin yorumunda ${ }^{46}$ öne çıkan Benjamin'in "Din olarak Kapitalizm” ${ }^{47}$ metni, kapitalizmde dünyadaki kaygıları, acıları ve tedirginlikleri azaltmaya yarayan dini bir yapı görmektedir. Buna göre tıpkı diğer dinler gibi külte sahiptir. Bu kültler süreklidir ve suçlayıcıdır [verschuldend]. Benjamin'in gözünde kapitalizm kefaret yerine suçluluk/borç üreten ilk örnektir ${ }^{48}$. "Kapitalizm dogması olmayan saf kült dinidir" ${ }^{49}$. Kapitalizm bilimcilik, yararcılık ve çıkarcılık gibi rasyonelleştirebildiği "dinsel” unsurları "tarafsızlık" içerisinde sunabilme kapasitesine sahiptir.

Löwy suçluluk ile borç kelimelerinin (Schuld) ortaklığını hatırlatarak Benjamin’in "ekonomik borç" ile "mitik suçluluk" arasında kurduğu ilgiyi hatırlatır ${ }^{50}$. Din olarak kapitalizm, sürekli borca ve suçluluğa dayalı bir büyüme halidir. Ne zaman tam olarak büyümüş ve gelişmiş olunur? Hiçbir zaman. Bu yüzden Benjamin kapitalizmin mezhepleri arasında bir ümit arayışı içerisinde değildir. Kalkınmacılıktan medet umulamayacağının farkındadır. "Ya sosyalizm ya barbarlık" sloganı bu anlamda bugün yeniden oluşmakta olan post-totaliter totalitarizm devletten özgürlüğe geçiş imkanını araştırmamaktadır.

Bu çerçevede Benjamin'in teknik okuması her şeyden önce teknik imkanlarla yaşanmakta olan güncel dünyadaki felaketi hatırlatmaktadır. Felaketi durduracak olan kendisini anti-kapitalist olarak niteleyen kimlikçi ekolojik hareketlerin kendisinden çok emin "anti-kapitalist" duruşundan ziyade, kapitalizm dininin heretiği söylemlerin suç ortaklığından da uzaklaşabileceğimiz yeni bir sıçramanın örgütlenmesidir. Yoksa kapitalizmin "suç ortaklığından” bütünüyle muaf olduğunu düşünen bir hareketin aktivizm yanılsaması zorunlu olarak felaketi durduran bir politik eylem değildir. Gerçek bir tarihsel deneyim, adına "ilerleme” denilen ya da adına "gelişme” denilen teknolojinin yönetimsel ilişkilerinin kırılmasıyla mümkün olabilir. Post-totaliter totalitarizmlerin içerisindeki "bireycilik" tutumunun, başka yeni totalitarizmlerin ceberut devlet baskısından daha erdemli ve işe yarar olduğunu düşünmek bir kurtuluşs sunmaz.

46 Michael Löwy, "Le capitalisme comme religion : Walter Benjamin et Max Weber", Raisons politiques, 2006/3 - N 23, 203-219.

47 Walter Benjamin, GS, VI, $100-104$.

48 Walter Benjamin, a.g.e., 100.

49 Walter Benjamin, a.g.e., 100.

50 Löwy, a. g. e., 208-209. 
Hakem Değerlendirmesi: Dış bağımsız.

Çıkar Çatışması: Yazar çkar çatış,ması bildirmemiștir.

Finansal Destek: Yazar bu çalışma için finansal destek almadığını beyan etmiştir.

Peer-review: Externally peer-reviewed.

Conflict of Interest: The author has no conflict of interest to declare.

Grant Support: The author declared that this study has received no financial support.

\section{Kaynaklar}

Adorno, W. Theodor. Walter Benjamin Üzerine. Çeviren D. Muradoğlu. İstanbul: YKY, 2012.

Benjamin, Walter. Gesammelte Schriften. Band I-1, Band I-2 Herausgegeben von Rolf Tiedemann und Hermann Schweppenhäuser. Frankfurt am Main: Suhrkamp, 1991.

-. Gesammelte Schriften. Band II-1, Band II-2 Herausgegeben von Rolf Tiedemann und Hermann Schweppenhäuser. Frankfurt am Main: Suhrkamp, 1991.

-. Gesammelte Schriften. Band III. Herausgegeben von Hella Tiedemann-Bartels. Frankfurt am Main: Suhrkamp, 1991.

-. Gesammelte Schriften. Band IV-1, Band IV-2. Herausgegeben von Tillman Rexroth. Frankfurt am Main: Suhrkamp, 1991.

-. Gesammelte Schriften. Band V-1, Band V-2. Herausgegeben von Rolf Tiedemann. Frankfurt am Main: Suhrkamp, 1991.

-. Gesammelte Schriften. Band VI, Herausgegeben von Tillman Rexroth. Frankfurt am Main: Suhrkamp, 1991.

-. Gesammelte Schriften. Band VII-1, Band VII-2. Herausgegeben von Rolf Tiedemann und Hermann Schweppenhäuser unter Mitarbeit von Christoph Gödde. Henri Lonitz und Gary Smith, Frankfurt am Main: Suhrkamp, 1991.

-. Werke und Nachlaß, Kritische Gesamtausgabe. Band 3: Der Begriff der Kunstkritik in der deutschen Romantik. hg. von Uwe Steiner. Berlin: Suhrkamp Verlag, 2008.

-. Werke und Nachlaß. Band 16: Das Kunstwerk im Zeitalter seiner technischen Reproduzierbarkeit. Herausgegeben von Burkhardt Lindner unter Mitarbeit von Simon Broll und Jessica Nitsche. Berlin: Suhrkamp, 2013.

-. Briefe I. Herausgegeben und mit Anmerkungen versehen von Gershom Scholem und Theodor W. Adorno. Frankfurt am Main: Suhrkamp Verlag, 1978.

-. Euvres I-II-II, Çeviren M. de Gandillac, P.Rusch et R.Rochlitz. Paris: Gallimard, 2000.

-. Paris capitale du XIXe siècle. Le livre des passages. Çeviren Jean Lacoste. Paris: le Cerf, 2002.

-. Correspondance 1 - 2, haz. T.W.Adorno et G. Scholem, Çeviren Guy Petitdemange. Paris: Aubier, 1979.

-. Technique et Expérience, Mélancolie de Gauche et Autres Textes. Çeviren M. de Gandillac, R. Rochlitz et P. Rusch \& P. Beck, B. Stiegler. Paris: Eterotopia France, 2016.

-. Son Bakışta Aşk, Walter Benjamin'den Seçme Yazılar. Çeviren N. Gürbilek. Hazırlayan N. Gürbilek. İstanbul: Metis, 2012.

-. Estetize Edilmiş Yaşam, Sanat'tan Savaş ve Siyasete Alman Faşizminin Kuramları. Çeviren Ünsal Oskay. İstanbul: Der Yayınları, 1995.

Gülenç, Kurtul. "Sınırda Olmak ya da Yaşamda Kalmanın Halleri”. Hazırlayan M. Ertan Kardeş, Dar Kapıdaki Mesih, Walter Benjamin ve Politik Felsefesi. İstanbul: İthaki, 2017, 61-77. 
Kardeş, M. Ertan. "Walter Benjamin'in Politik Felsefesine Dair Öğeler”. Hazırlayan M. Ertan Kardeş. Dar Kapıdaki Mesih, Walter Benjamin ve Politik Felsefesi. İstanbul: İthaki, 2017, 29-48.

Leslie, Esther. Walter Benjamin. London: Reaktion Books, 2007.

Lukács, György. Tarih ve Sınıf Bilinci. Çeviren Y. Öner. İstanbul: Belge, 1998.

-. Roman Kuramı. Çeviren C. Soydemir. İstanbul: Metis, 2003.

Löwy, Michael. "Le capitalisme comme religion: Walter Benjamin et Max Weber”. Raisons politiques. 2006/3 $-\mathrm{N}^{\circ} 23,203-219$.

Meyer, Alfred Gotthold. Construire en fer, Histoire et esthétique. Hazırlayan Walter Benjamin, Çeviren M. Roffi, L. Biétry. Paris: InFolio, 2005.

Scheerbart, Paul. Lesabéndio: Bir Asteroid Romanı. Çeviren Ç. Ünaltay. İstanbul: Paris Yayınları, 2017.

-. Glass Architecture, Çeviren J. Palmes. Hazırlayan Dennis Sharp. New York: Praeger, 1972, 41-74.

Sieber, Jan. "Walter Benjamin's Concept of Technique”. Anthropology \& Materialism. 4, 2019.

Pulliero, Marino. Le Désir d'authenticité. Walter Benjamin et l'héritage de la Bildung allemande. Paris: Bayard, 1002-1005.

Steiner, Uwe. Walter Benjamin, An Introduction to his Work and Thought. Çeviren M. Winkler. Chicago and London: The University of Chicago Press, 2010.

Witte, Bernd. Walter Benjamin. Çeviren M. Tüzel. İstanbul: YKY, 2002.

Wohlfarth, Irving. "Spielraum. Jeu et enjeu de la "seconde technique" Walter Benjamin". Anthropologischer Materialismus, Materialismus der Begegnung. MoMo Berlin Philosophische KonTexte. Band 4. Marc Berdet / Thomas Ebke (dir./Hg.) 2014, 75-141. 